\title{
Análise do rendimento no primeiro serviço em tenistas de competição sob o efeito de um escoamento aerodinâmico induzido
}

CDD. 20.ed. 152.3

796.34

\author{
Pedro Cabral MENDES ${ }^{* * * *}$ \\ Rui MENDES*/*** \\ Fernando MARTINS*/**** \\ Manuel António FACAS VICENTE \\ J uan Pedro FUENTES \\ Ruperto MENAYO \\ Gonçalo DIAS*
}

*Faculdade de Ciências do Desporto e

Educação Física, Universidade de Coimbra - Portugal.

**Escola Superior de Educação de Coimbra - Portugal.

***Universidade Técnica de Lisboa - Portugal

****Instituto de Telecomunicações, Pólo de Coimbra, Delegação da Covilhã - Portugal.

*****Instituto de Enge-

nharia de Sistemas e Computadores, Coimbra - Portugal.

****** Faculdade de Ciências e Tecnologia, Universidade de Coimbra - Portugal.

*******Faculdad de Ciencias del Deporte, Universidad de Extremadura, Cáceres - Espanha.

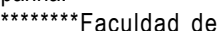
Ciencias, de la Actividad Física y del Deporte, Universidad Católica San Antonio, Murcia - Espanha.

\section{Introdução}

$\mathrm{Na}$ prática esportiva, as condiçōes do envolvimento (i.e., ambientais) são decisivas na realização da tarefa apesar de difícil intervenção por parte do treinador (ELLIOTT, CRESPO \& ReID, 2009). O estudo sobre os efeitos dos constrangimentos ambientais no processo de aquisição e de produção de movimentos e em particular os de natureza climatérica (e.g., vento, chuva, temperatura, luminosidade natural, umidade), até à data pouco analisados, implicam o desenvolvimento de sistemas, instrumentos e procedimentos complexos, mas necessários para criar condições de simulação próximas da realidade ecológica em que muitos movimentos e ações motoras são produzidas (Mendes, Simôes, Mendes, Trovão, Luz, Couceiro, Ferreira, Dias \& Fuentes, 2010a).

O estudo realizado por Mendes, Mendes, Fuentes, Campos, Menayo e Araújo (2011) com treinadores de tênis, o qual analisou os fatores de rendimento no primeiro serviço em tenistas de competição, demonstra que o vento é o fator ambiental mais importante no rendimento do primeiro serviço. A relevância deste fator ambiental já tinha sido reconhecida por diversos autores (ELLIOTT, REID \& CRESPO, 2009; Faulkner, 1997; Flanagan, 1983; Hoskins, 2003; Loehr, 1996; SCOTt \& Randy, 2000).

Por seu lado, ao analisar-se as características do tênis moderno, verifica-se um aumento da velocidade do jogo, o que faz do serviço um gesto técnico com grande importância em contexto competitivo (GIRARD, Micallef \& Millet, 2005; HaAke, Chadwick, Dignall, Goodwill \& Rose, 2000; Lees, 2007; Menayo, Fuentes, Moreno, Clemente \& García Calvo, 2008; TANaBe \& ITO, 2007). O rendimento do serviço não depende só da velocidade da bola mas igualmente da sua colocação (exatidão) e daí $o$ interesse que tem gerado no seio da comunidade 
científica o estudo sobre como se relacionam estas duas variáveis de produto (ATKINSON \& SPEIRS, 1998; Cauraugh, Gabert \& White, 1990; Johnson, 1957; KNudSON, Noffal, BaHAMONDE, BAUER \& BlaCKWELl, 2004; Menayo, 2010; Menayo et al., 2008). Com o propósito de dar um contributo a esta preocupação temática, pretende-se estudar a velocidade da bola, a exatidão e a precisão em tenistas de competição quando constrangidos por um escoamento aerodinâmico induzido ("vento lateral artificial").

Os protocolos de medição da exatidão de natureza discreta utilizados por JoHNSON (1957), CAURAUGH, Gabert e White (1990), Signorile, Sandler, Smith, Stoutenberg e Perry (2005), Menayo et al. (2008) e BonNefoy, SlaWinski, LeVEque, Riquet e Miller (2009) baseiam-se na atribuição de um determinado valor por zonas específicas da quadra de tênis. Um outro sistema de medida alternativo ao discreto recorre ao método contínuo a partir da determinação das coordenadas do ponto exato onde a bola ressaltou na quadra (CARLTON, Chow \& Shim, 2006; Menayo, 2010; Mendes, MenDes, Martins, Facas Vicente \& Fuentes, 2010b).

A velocidade de saída da bola por norma é medida com recurso a um radar fixo numa quadra de tênis regulamentar (Carlton, ChOw \& Shim, 2006; Girard, Micallef \& Millet, 2005, 2007; Menayo, 2010; Menayo et al., 2008; Pugh, Kovaleski, Heitman \& Gilley, 2003).

\section{Método}

\section{Amostra}

Participaram no estudo voluntariamente 12 sujeitos (do sexo masculino), destros e com uma idade de 25,17 \pm 3,93 anos. Relativamente às suas caraterísticas antropométricas, o grupo de jogadores, detinha uma estatura de 1,77 $\pm 0,06$ metros, uma envergadura de $1,81 \pm 0,05$ metros e uma massa corporal de 72,29 $\pm 4,17$ quilogramas.

A média de anos de experiência na prática do tênis situou-se nos 16,25 $\pm 5,56$ anos, enquanto que a média de anos de prática competitiva federada correspondeu a 13,67 $\pm 4,29$ anos. O estudo foi realizado em conformidade com o código de ética da Universidade de Coimbra e as recomendaçôes da Declaração de Helsínque em Pesquisa com Seres Humanos. Nenhum sujeito sofria de qualquer tipo de incapacidade física ou mental.
Importa clarificar que a exatidão é, com frequência, erroneamente confundida com a precisão, quando na prática são conceitos distintos. Enquanto que a exatidão diz respeito à amplitude do erro cometido e daí tratar-se de uma medida de localização, a precisão refere-se à proximidade de várias medições, o que a faz ser uma medida de dispersão (BrASIL, 1995; INTERNATIONAL ORGANIZATION FOR STANDARDIZATION, 2007; Instituto PoRTUGUês dA QuAlidade, 2007).

Não são conhecidas pesquisas que tenham relacionado a velocidade da bola, a exatidão e a precisão sob o efeito de um escoamento aerodinâmico induzido no serviço. Este gesto técnico assume um papel decisivo no tênis atual (Araújo \& Carvalho, 2007; Brody, 2003; HaAKE et al., 2000; TANABE $\&$ Iто, 2007), pelo que o estudo das relaçōes entre as referidas variáveis permite estudar a variabilidade das condiçóes de prática e o envolvimento onde esta se desenvolve.

Face ao exposto, o presente trabalho tem como objetivo, conceber um protocolo experimental de medida da exatidão e da velocidade para o serviço de tênis e verificar as seguintes hipóteses de estudo: 1) se o efeito do Escoamento Aerodinâmico induzido (EAI) ou vento artificial tem influência no rendimento do primeiro serviço plano em jogadores de tênis experientes e; 2) se a velocidade e a exatidão se relacionam sob o efeito do EAI.

\section{Tarefa}

O gesto requerido foi o primeiro serviço plano do tênis, realizado atrás da linha de fundo da quadra de tênis, do lado direito e a $0,80 \mathrm{~m}$ de distância da marca central. A quadra de tênis coberta detinha as dimensōes regulamentares na variante de singulares, $23,77 \mathrm{~m}$ de comprimento e $8,23 \mathrm{~m}$ de largura.

\section{Delineamento experimental}

Todos os tenistas serviram um bloco de 20 tentativas sem qualquer constrangimento de EAI e realizaram mais quatro blocos de 20 tentativas em diferentes situaçôes de prática: 1$)$ velocidade mínima de EAI $(2,4 \mathrm{~m} / \mathrm{s}) ; 2)$ velocidade média de $\operatorname{EAI}(4,3$ $\mathrm{m} / \mathrm{s}) ; 3)$ velocidade máxima de EAI $(5,8 \mathrm{~m} / \mathrm{s})$ e; 4$)$ velocidade aleatória de EAI (sequências aleatórias 
das três velocidades de EAI). Tendo como objetivo controlar o possível efeito nefasto de uma condição de prática sobre a outra (erro progressivo), procedeuse ao contra balanceio da ordem das referidas quatro condiçōes de prática.

A variável independente correspondeu à estruturação da prática motora utilizada nas quatro condiçôes de prática sob o efeito do EAI já referenciadas. As medidas da variável dependente, a exatidão, foram: o erro radial (RE) e o erro absoluto (AE). O erro radial calculouse com base na medida da distância absoluta até ao centro do alvo (Van Den Tilaar \& ETtema, 2003) e o absoluto determinado a partir do valor absoluto do desempenho, i.e., do valor em módulo ignorando o sinal positivo ou negativo do resultado (GoDINHO, Mendes, Melo \& BarReiros, 2000; SCHMidT, 1988). Para a análise da precisão utilizou-se o erro variável (VE) que mede a variabilidade ou consistência da resposta face aos resultados em torno da resposta média e a variabilidade Total (E) que combina os erros constante e variável e exprime a variabilidade total de um conjunto de respostas em relação ao valor critério da tarefa (GodinHo et al., 2000; SCHMIDT, 1988). Quanto à velocidade do serviço, teve-se em conta a velocidade máxima de saída da bola.

O delineamento experimental é ilustrado na sua generalidade (FIGURA 1), considerando para o efeito os dispositivos experimentais e as variáveis de estudo.

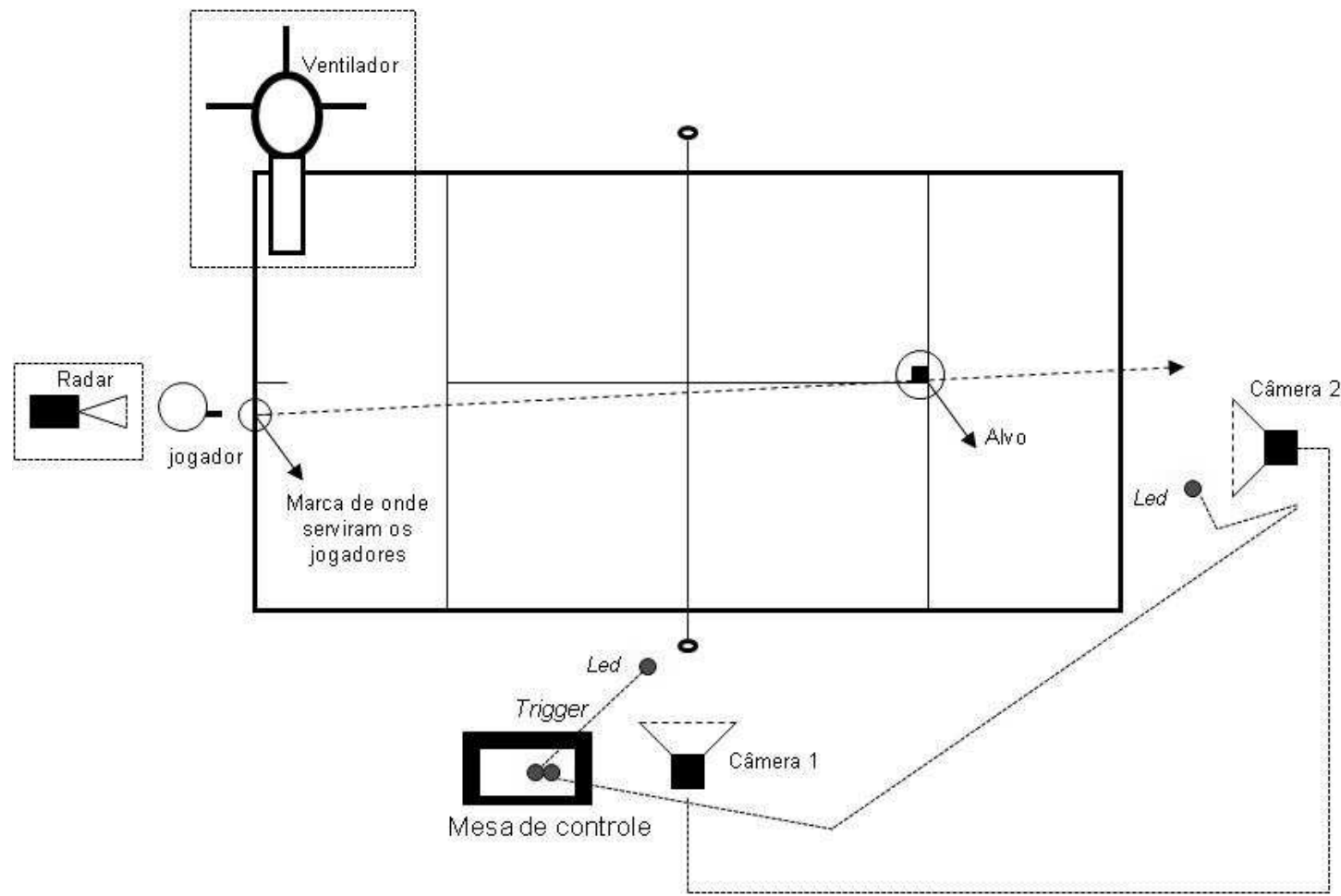

FIGURA 1 - Delineamento experimental (vista superior).

\section{Dispositivo de escoamento aerodinâmico induzido}

A produção de um EAI fez-se a partir da adaptação de um ventilador industrial helicoidal da marca METEC - HCT - 45 - 4T. Instalou-se no ventilador um variador eletrônico de velocidade, da marca SEW Eurodrive, ao qual foi acoplado um potenciômetro com 11 posições, o que permitiu regular a velocidade do motor em função da sua posição. De modo a homogeneizar o fluxo de ar, fixou-se à saída do ventilador uma malha em inox de $0,0045 \mathrm{~m}$ e uma conduta de $1,20 \mathrm{~m}$ de comprimento e de $0,45 \mathrm{~m}$ de diâmetro (MeNDES et al., 2010a).
Em virtude dos participantes no estudo apresentarem diferentes estaturas (e, consequentemente, lançamentos de bola variáveis) e aliado ao fato do ventilador descrito ter um diâmetro de $0,45 \mathrm{~m}$, houve necessidade de conceber uma estrutura elevatória capaz de regular o ventilador em altura. A solução passou por adaptar um elevador telescópico do Modelo GUIL ELC - 506, com capacidade para elevar uma carga máxima de $250 \mathrm{~kg}$ e até uma altura máxima de $5,20 \mathrm{~m}$. A validação do ventilador pressupôs a seleção de três velocidades de EAI a utilizar no estudo. Para o efeito, trataram-se os dados diários da velocidade de vento na cidade da Figueira da Foz durante o ano de 2009, cedidos pelo Instituto de Meteorologia de Portugal. 
A velocidade média diária foi de 2,54 $\pm 1,105 \mathrm{~m} / \mathrm{s}$ e a média da velocidade máxima diária de 9,91 $\pm 3,331$ $\mathrm{m} / \mathrm{s}$. Assumiu-se como velocidade mínima a posição 4 do ventilador, $2,4 \mathrm{~m} / \mathrm{s}$, pela proximidade ao valor $\mathrm{da}$ velocidade média diária na cidade da Figueira da Foz e, para as restantes velocidades, respeitou-se o critério da equidistância entre as três velocidades. Para a velocidade média definiu-se a posição 7 do ventilador, $4,3 \mathrm{~m} / \mathrm{s}$, e relativamente à velocidade máxima a opção recaiu na posição $10,5,8 \mathrm{~m} / \mathrm{s}$.

Após uma análise ao ruído provocado pelo ventilador nas 11 posições através de um sonômetro analisador de Ruído 2260 Investigator, verificou-se que as posiçōes $6,7,8$, 9 e 10 apresentam valores superiores a $75 \mathrm{~dB}(\mathrm{~A})$, valor considerado como indicador de desconforto acústico (OMS, 2002). Para proteção do tenista, seleccionou-se o protector auricular Howard Leight: Smart fit, capaz de reduzir as exposiçōes ao ruído, nas 11 posiçōes do variador, para valores que não ultrapassam $76 \mathrm{~dB}(\mathrm{~A})$, não interferindo, dessa forma, os níveis sonoros excessivos no equilíbrio do atleta (MENDEs et al., 2010a).

A calibração do ventilador a cada tenista da amostra implicou um estudo prévio e que consistiu na análise da média do ponto mais alto da bola e do ponto de impacto em 20 primeiros serviços realizados. Determinado este valor por jogador e atendendo ao fato do ventilador ter um caudal de fluxo de ar homogêneo num diâmetro de $0,60 \mathrm{~m}$ em todas as posiçōes do potenciômetro do ventilador, estipulou-se que o bordo superior da conduta seria posicionado à mesma altura média do ponto mais alto da bola durante o lançamento.

\section{Dispositivo de medição da exatidão no serviço}

A medição da exatidão realizou-se a partir da análise $2 \mathrm{D}$ e consequentemente do cálculo da profundidade do serviço ou localização antero-posterior ( $\operatorname{coordenada} x$ ) e a direção do serviço ou localização lateral (coordenada $y$ ) do ponto correspondente ao primeiro quique da bola após o impacto com a raquete. Para tal, recorreu-se a uma câmera digital Casio Exilim Pro Ex-F1, que filmou a $300 \mathrm{~Hz}$ por segundo, designada por câmera 2 (FIGURA 2), fixa a um tripé (5,04 $\mathrm{m}$ de altura) e direcionada para o lado contrário da quadra onde se encontrava o sujeito e a visualização de um "led" ("light-emitting diode"). Para a calibração do espaço utilizaram-se quatro pontos, com o ponto $(0,0)$ do sistema de referência a coincidir com o ponto de interseção da linha central com a linha de serviço, i.e., o alvo (vd. FIGURA 2).

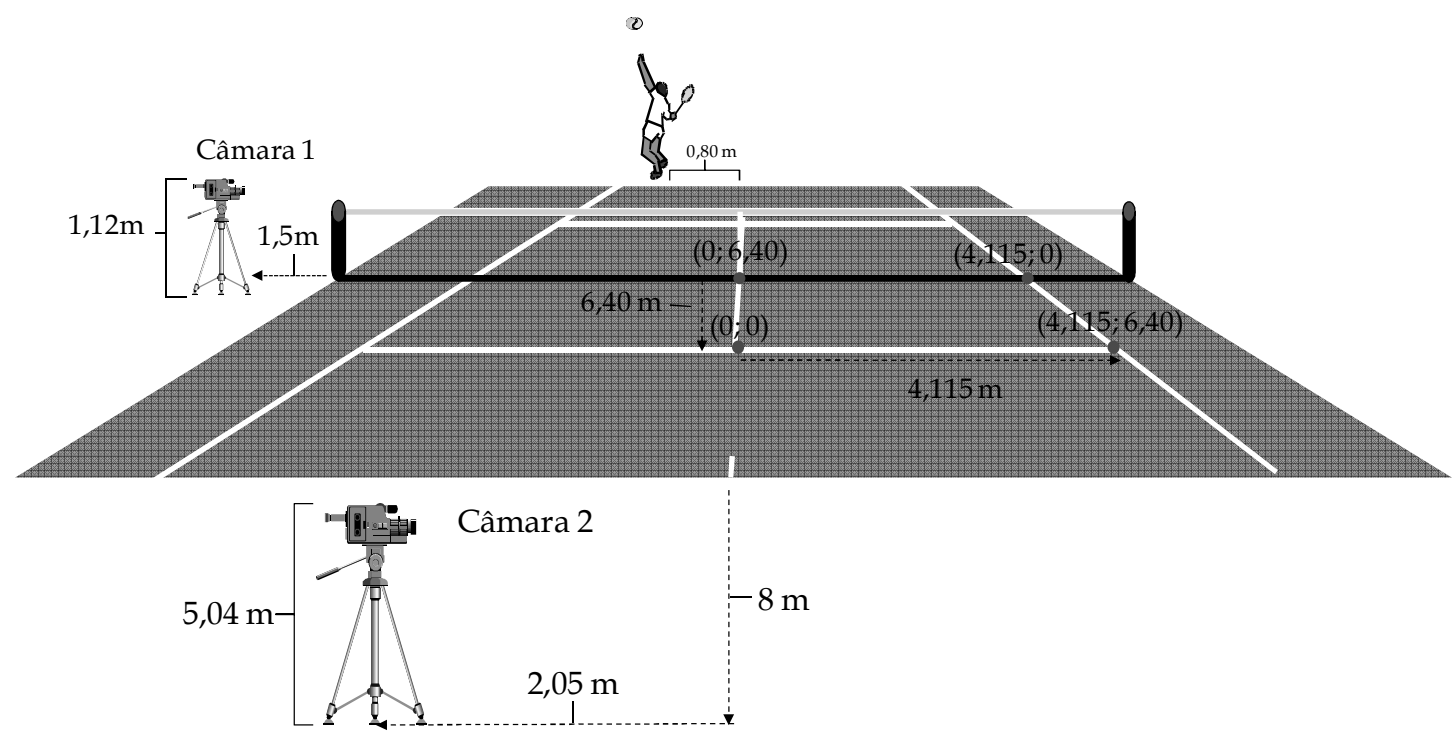

FIGURA 2 - Sistema de referência da quadra de tênis.

Atendendo ao elevado número de tentativas por sujeito (i.e., 100 primeiros serviços) e à natureza balística do próprio gesto, a opção de repetir todos os serviços que tocassem a rede poderia constranger a pesquisa, ao provocar efeitos de prática indesejados e não controlados pela repetição sucessiva dessas tentativas inválidas. Por outro lado, ao não serem analisadas as localizaçôes das tentativas que tocam na rede, desconhecer-se-ia o efeito que poderiam ter no estudo (CARLton, ChOW \& SHIM, 2006).

Neste sentido criou-se um sistema de ponderação (por penalização) do erro radial (RE) para medir a exatidão no serviço de tênis quando as bolas intersetam a rede, ou seja, ao RE medido adiciona-se 
uma penalização. Concebeu-se uma rede de tênis adaptada com tiras de 0,02 $\mathrm{m}$ de largura e 1,00 $\mathrm{m}$ de comprimento, de tecido estrafor e com um espaçamento entre tiras de $0,02 \mathrm{~m}$, que permitisse o registo do instante da interseção, bem como a não alteração da trajetória da bola após o contato com a rede. Para o efeito, validou-se a rede no mesmo local onde decorreu a investigação e os dados permitiram verificar a inexistência de diferenças estatisticamente significativas entre o bloco de 50 tentativas sem rede e o bloco de 50 tentativas com a rede, obtendo um coeficiente de variação $(\mathrm{CV})$ inferior a $1 \%$. A garantia da constância da trajetória da bola sempre que toca na rede adaptada viabiliza a sua utilização nesta pesquisa. Para evitar que duas tentativas tenham o mesmo valor de RE, independentemente se bate na rede adaptada ou a sobrepõe, desenvolveu-se um sistema de penalização.
O sistema de penalização inicialmente desenvolvido (MENDES et al., 2010b) é discreto e constituído por 10 zonas de penalização. A zona 1 ao incluir a seção da rede mais próxima do solo foi associada à maior penalização e a zona 10 à menor penalização por corresponder à seção superior da rede (TABELA 1). A determinação do erro radial total (TRE) para as tentativas que tocaram na rede obteve-se a partir do somatório do erro radial medido (MRE) com o valor de penalização.

As zonas de penalização são designadas de um a 10 (ascendentemente) e a altura da rede em cada zona é obtida pela função:

$$
h(n)=f(n) \times(91,5-l)
$$

onde $f(n)=\frac{1}{2(n+1)}, 1 \leq n \leq 10, n \in \mathrm{N}, \sum_{i=1}^{10} f(i) \approx 1$ e $l$ o valor da largura da tela.
$(0,0)$

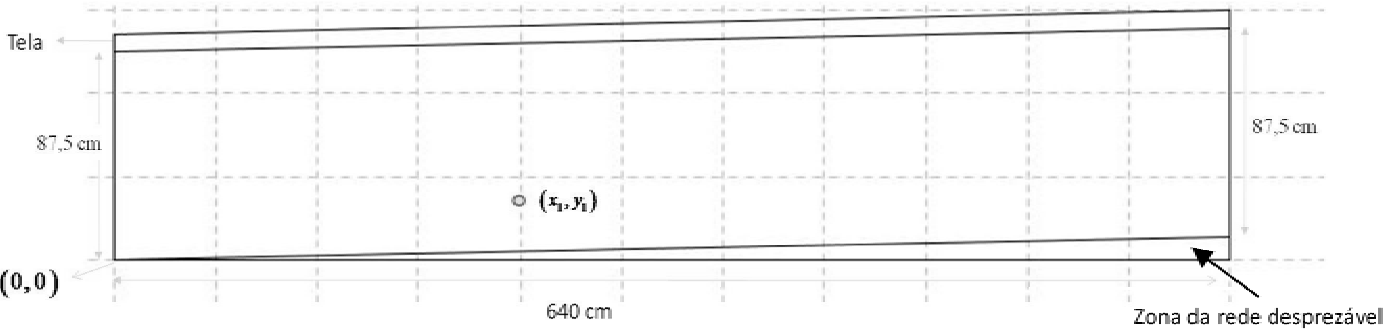

FIGURA 3 - Vista frontal de metade da rede de tênis.

Considerando um serviço que intersecte a rede num ponto $\left(x_{1}, y_{1}\right)$, conforme a FIGURA 3, a obtenção da respectiva zona de penalização $(n)$, realiza-se segundo o algoritmo:

1) Determinação de $y_{z p}: y_{z p}=y_{1}-\left|x_{1}\right| \times \frac{25}{1128}$

o $y_{\text {zp }}$ é o valor da altura da rede após a subtração da porção, correspondente, da rede a desprezar. Este procedimento justifica-se pelo fato da rede não ter a mesma altura no centro e nas suas extremidades.

2) Através da TABELA 1 obtém-se o valor de $n$.

TABELA 1 - Zonas de penalização para o sistema de penalização discreto.

\begin{tabular}{cc}
\hline Zonas de penalização & $\boldsymbol{y}_{z p} \in[\boldsymbol{a}, \boldsymbol{b}[$ \\
\hline 1 & {$[0 ; 21,88[$} \\
2 & {$[21,88 ; 36,46[$} \\
3 & {$[36,46 ; 47,40[$} \\
4 & {$[47,70 ; 56,15[$} \\
5 & {$[56,15 ; 63,44[$} \\
6 & {$[63,44 ; 69,69[$} \\
7 & {$[69,69 ; 75,16[$} \\
8 & {$[75,16 ; 80,02[$} \\
9 & {$[80,02 ; 84,40[$} \\
10 & {$[84,40 ; 87,5]$} \\
\hline
\end{tabular}

O TRE a considerar na exatidão dos serviços que intersectem a rede na zona de penalização $n$ é dado pela relação:

$$
\mathrm{TRE}=\mathrm{MRE}+p(n),(2)
$$

onde $p(n)=f(n) \times 548,51 \leq n \leq 10$ e $n \in \mathrm{N}$.

O caso discreto, ao fundamentar-se num sistema de zonas penaliza com a mesma grandeza tentativas que intersectem a rede em alturas diferentes mas localizados na mesma zona de penalização. Ou seja, o exemplo de uma tentativa que toque na rede na parte inferior da zona 4 (TABELA 1) terá a mesma penalização que outra tentativa que intersete a rede na parte superior da referida zona. No intuito de desenvolver um sistema mais consentâneo com a realidade que se pretende modelar, concebeu-se uma solução contínua, onde uma determinada localização da bola na rede tenha a correspondente penalização dada por uma função suave.

Para o caso contínuo, a determinação do TRE de um serviço que intersete a rede num ponto efetua-se recorrendo ao seguinte processo:

$$
\mathrm{TRE}=\mathrm{MRE}+p(x, y),(3)
$$


em que a penalização $p(x, y)$ é obtida através da expressão:

$$
p(x, y)=\frac{1}{0,2\left(y-|x| \frac{25}{1128}+1\right)} \times 548,5
$$

O objetivo de utilizar todas as tentativas para o estudo da exatidão e da precisão, pressupõe uma diferenciação na localização (primeiro quique na quadra de tênis) entre os serviços que intersetem a rede e os que a sobrepõem. Assim, para a determinação de uma nova localização de uma tentativa que toque na rede e ressalte numa localização $(a, b)$ efetuam-se os seguintes procedimentos:

1) Determinar o TRE.

2) Determinar as novas coordenadas $\left(a^{\prime}, b^{\prime}\right)$ através das seguintes expressões:

$$
a^{\prime}=a+\frac{(T R E-M R E) a}{M R E}
$$

$$
b^{\prime}=b+\frac{(T R E-M R E) b}{M R E}
$$

pelas quais se pretende introduzir perturbaçōes de erro nas coordenadas $(a, b)$ proporcionais a estas e considerando a penalização adicionada ao MRE.

O registo do momento (i.e., frame) da interseção da bola na rede fez-se através de uma outra câmara digital Casio Exilim Pro Ex-F1, denominada por câmara 1 (FIGURA 4), colocada sobre um tripé (com 1,12 m de altura) e alinhada com a rede de tênis e a um "led". A calibração da rede pressupôs um sistema de referência de seis pontos, com o ponto $(0,0)$ a coincidir com o apoio central da rede no solo (FIGURA 4). A obtenção das coordenadas reais do ponto de interseção na rede realizou-se a partir do "tracking" manual (2D) no programa Kwon 3.16 ${ }^{\circledR}$. Para a sincronização entre as duas câmaras recorreuse a um sincronizador composto por um "trigger" e dois "leds", um por câmara de filmar.

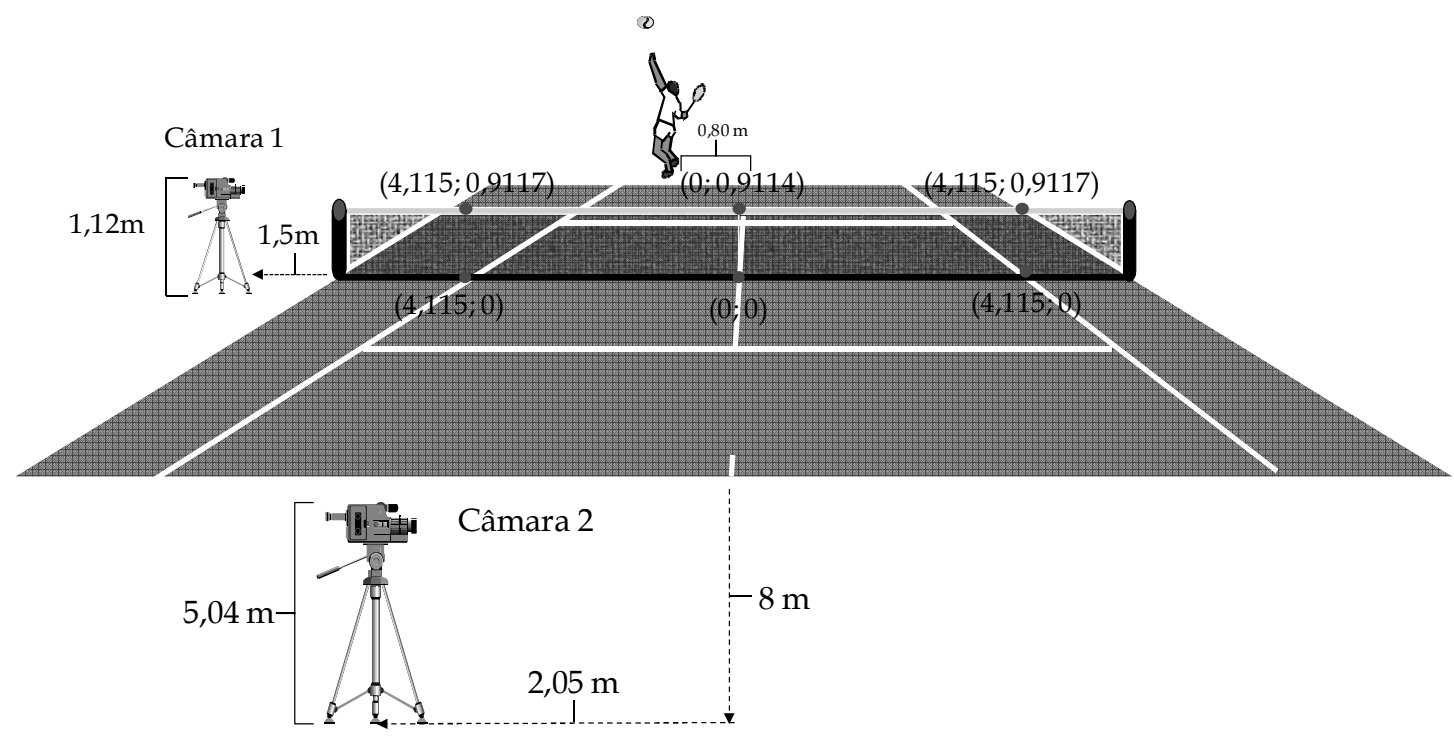

FIGURA 4 - Sistema de referência da rede.

\section{Dispositivo de medição da velocidade de saída da bola}

O registo da velocidade de saída da bola após o impacto foi realizado através de um radar da marca, Stalker $^{\circledR}$ modelo Sport, que registou a velocidade da bola com uma exatidão de $+/-1,61 \mathrm{~km} / \mathrm{h}$ e uma amplitude de medição de 8,05 a $400 \mathrm{~km} / \mathrm{h}$. Quanto ao método de registo, o radar foi posicionado a $2 \mathrm{~m}$ de distância atrás do jogador e a uma altura variável de sujeito para sujeito durante a prática motora.
Este procedimento justifica-se pelas diferenças de estatura dos participantes e as consequentes variações dos pontos de impacto. Desta forma, minimizou-se o efeito cosseno durante a medição (AlvEs, 1996).

\section{Procedimentos}

Os sujeitos foram analisados individualmente e informados sobre o objetivo da tarefa para os 100 serviços previstos no estudo, ou seja, servir à máxima velocidade e com exatidão para o ponto de interseção 
da linha central e linha de serviço (ponto “T”). No propósito de preparar fisiologicamente os participantes para o esforço, realizaram uma mobilização funcional e articular de cinco minutos seguido de um período de cinco minutos para a realização obrigatória de pelo menos oito serviços prévios a uma intensidade crescente. Durante a recolha de dados o indivíduo não recebeu qualquer informação verbal sobre a qualidade do movimento, nem sobre o resultado de cada tentativa (observava apenas o resultado).

Os jogadores participaram em cinco condições de prática, cada uma com 20 tentativas. Na primeira, serviu sem EAI, e nas seguintes a uma velocidade mínima, média, máxima e aleatória (variação das três velocidades de EAI). Respeitou-se o tempo de recuperação entre pontos previsto no quadro regulamentar da modalidade (que é de 20 segundos) e estipulou-se 180 segundos entre as cinco condições de prática, de 20 tentativas cada. A eficácia dos referidos tempos de recuperação, foi testada num estudo piloto realizado com três jogadores não pertencentes à amostra. $\mathrm{O}$ jogador utilizou sempre os protetores auriculares e apenas iniciava o movimento de serviço quando visualizava os "leds" acesos do "trigger".

\section{Resultados}

\section{Análise intra-individual}

A análise da exatidão do desempenho dos jogadores da amostra realizou-se a partir das medidas de AE e de RE. Nas cinco condições realizadas, verificou-se que todos os jogadores apresentam valores superiores de $\mathrm{AE}$ no eixo dos $y$, ou seja, os jogadores quando servem têm menor exatidão na profundidade (localização antero-posterior, eixo $y$ ) e maior exatidão na direção (localização lateral ou eixo x). A heterogeneidade dos dados obtidos para o AE foi elevada nos dois eixos e nas cinco condiçōes (sem e com AEI), como comprovam os valores encontrados nos coeficientes de variação $(\mathrm{CV})$, sempre superiores a $50 \%$.

A média do RE na totalidade dos 100 serviços por sujeito é na sua generalidade superior a $1 \mathrm{~m}$ e inferior a $3 \mathrm{~m}$, ou seja valores elevados de erro face ao alvo. Os CV do RE nos cinco blocos de serviços e para a generalidade dos 12 sujeitos apresentam valores altos, superiores, em muitos casos, a $50 \%$ o que sugere uma elevada dispersão dos dados.

\section{Análise estatística}

Foi calculada a média e o coeficiente de variação do RE, AE e da velocidade do serviço para cada estudo de 20 tentativas. A fim de verificar a existência de uma distribuição Gaussiana como requisito prévio para a análise da variância, utilizou-se o teste de normalidade de Kolmogorov-Smirnov. De modo a verificar a existência de diferenças estatisticamente significativas nas distribuiçōes entre os sujeitos para cada velocidade de EAI (intra-individual) recorreu-se ao teste não paramétrico de Kruskal-Wallis.

Para efeitos de verificação de diferenças no RE entre as cinco condiçôes de 20 tentativas (interindividual), utilizou-se a análise de Variância (ANOVA). Relativamente à velocidade de saída da bola optou-se pelo teste de Kruskal-Wallis.

A relação entre as variáveis, erro radial e a velocidade de saída da bola, foi analisada com base nos coeficientes de correlação de Pearson e de Spearman. O nível de significância utilizado em todos os testes foi o nível standard de 5\%. Toda a análise estatística apresentada neste trabalho recorreu ao programa IBM SPSS Statistics (versão 19).

O teste Kolmogorov-Smirnov permitiu verificar para o RE uma distribuição Gaussiana apenas nos participantes 2 e 10. Aplicou-se a ANOVA e não se verificaram diferenças significativas entre as cinco condiçôes, tanto no participante $2\left(\mathrm{~F}_{4,95}=0,358\right.$, p-valor $\left.>0,05\right)$, como no participante $10\left(\mathrm{~F}_{4,95}=0,560\right.$, $\mathrm{p}$-valor $\left.>0,05\right)$, aceitando-se portanto a hipótese nula deste teste onde p-valor denota o nível de significância observado. Para os restantes sujeitos da amostra, recorreu-se ao teste não paramétrico de Kruskal-Wallis e foi possível constatar que todos os sujeitos, exceituando o sujeito 12 (p-valor $=0,003$ ), apresentam uma distribuição normal do RE nas cinco condiçōes realizadas. Apesar da elevada dispersão dos dados dos 12 sujeitos da amostra nas cinco condiçōes para o RE, não se verificaram diferenças estatisticamente significativas na presença de EAI, em 11 participantes da amostra.

Em conformidade com o descrito para o AE, constata-se igualmente uma tendência tanto no $\mathrm{VE}$ como na $\mathrm{E}$ (medidas de precisão), em todos os sujeitos da amostra, para valores superiores no eixo dos y nas cinco condições de prática. 
Com efeito, a amplitude no eixo dos $x$ para o VE variou de $0,49 \mathrm{~m}$ a $1,42 \mathrm{~m}$ e na $\mathrm{E}$ de $0,52 \mathrm{~m}$ a 1,85 $\mathrm{m}$. Relativamente ao eixo dos $y$ a amplitude foi de $0,52 \mathrm{~m}$ a $1,85 \mathrm{~m}$ no VE e de $1,25 \mathrm{~m}$ a $3,15 \mathrm{~m}$ na E. Tanto a exatidão como a precisão no eixo dos $x$ é maior do que no eixo dos $y$ em todos os sujeitos da amostra e nos cinco estudos efetuados.

Relativamente às medidas de dispersão em estudo, não se verifica qualquer padrão ou tendência, seja no aumento do erro em função do aumento do EAI ou vice-versa.

Os 12 participantes registaram nas cinco condições de prática, velocidades de serviço com uma amplitude de 140,20 a 178,20 km. Contrariamente ao que foi verificado no AE e RE, registou-se uma menor variação dos $\mathrm{CV}$ em todos os sujeitos da amostra, não excedendo os $10 \%$ (TABELA 2).

TABELA 2 - Médias e Coeficientes de variação da velocidade de saída da bola por sujeito e estudo.

\begin{tabular}{|c|c|c|c|c|c|c|c|c|c|c|}
\hline \multirow{2}{*}{ Suj. } & \multirow{2}{*}{$\begin{array}{c}\text { EAI 0 } \\
\bar{X}\end{array}$} & \multicolumn{3}{|c|}{ EAI 1} & \multirow{2}{*}{$\frac{\text { EAI } 2}{\bar{X}}$} & \multicolumn{2}{|r|}{ EAI 3} & \multicolumn{3}{|c|}{ EAI a } \\
\hline & & $\mathrm{CV}$ & $\bar{X}$ & $\mathrm{CV}$ & & $\mathrm{CV}$ & $\bar{X}$ & $\mathrm{CV}$ & $\bar{X}$ & $\mathrm{CV}$ \\
\hline 1 & 161,40 & 10,03 & 159,75 & 9,40 & 161,30 & 0,06 & 162,20 & 6,05 & 161,55 & 8,82 \\
\hline 2 & 176,85 & 7,29 & 177,90 & 2,81 & 176,85 & 2,98 & 178,20 & 3,04 & 164,15 & 7,63 \\
\hline 3 & 162,55 & 4,21 & 159,45 & 5,36 & 158,25 & 6,92 & 163,00 & 3,27 & 164,40 & 3,45 \\
\hline 4 & 150,80 & 4,39 & 152,05 & 4,95 & 149,25 & 2,68 & 151,50 & 5,07 & 144,95 & 6,19 \\
\hline 5 & 171,00 & 4,28 & 176,45 & 3,98 & 173,35 & 9,53 & 177,50 & 2,58 & 171,15 & 4,31 \\
\hline 6 & 156,00 & 4,12 & 152,05 & 4,64 & 157,90 & 5,25 & 154,70 & 6,01 & 153,85 & 4,95 \\
\hline 7 & 160,85 & 4,35 & 148,80 & 4,75 & 151,25 & 5,78 & 158,10 & 2,55 & 150,25 & 6,87 \\
\hline 8 & 150,15 & 3,37 & 151,20 & 4,55 & 150,80 & 4,68 & 151,60 & 4,40 & 150,25 & 4,92 \\
\hline 9 & 146,85 & 2,44 & 152,95 & 2,60 & 150,35 & 5,11 & 151,95 & 3,33 & 142,30 & 7,33 \\
\hline 10 & 171,85 & 3,49 & 172,85 & 3,31 & 174,00 & 2,21 & 171,00 & 3,95 & 173,65 & 4,28 \\
\hline 11 & 146,45 & 3,19 & 150,45 & 4,27 & 144,70 & 5,15 & 143,15 & 4,75 & 140,20 & 9,35 \\
\hline 12 & 150,50 & 4,97 & 151,35 & 3,90 & 156,85 & 3,06 & 151,30 & 2,21 & 151,75 & 3,74 \\
\hline Total & 158,22 & 0,09 & 158,55 & 0,09 & 157,82 & 0,09 & 159 & 0,08 & 155,47 & 0,09 \\
\hline
\end{tabular}

Aplicou-se o teste de Kolmogorov-Smirnov por condição de prática e por participante e, verificouse em todos os participantes, uma distribuição não Gaussiana da velocidade de serviço em pelo menos numa das cinco condições. O teste Kruskal-Wallis permitiu constatar que os participantes 1 ( $\mathrm{p}$-valor $=0,91), 3(\mathrm{p}$-valor $=0,38), 6(\mathrm{p}$-valor $=0,14), 8$ $(\mathrm{p}$-valor $=0,93), 10(\mathrm{p}$-valor $=0,60)$ e $12(\mathrm{p}$-valor $=$ $0,13)$ apresentam uma homogeneidade nas amostras ao longo das cinco condições de prática, ou seja, não se constatam diferenças estatisticamente significativas na distribuição da velocidade do serviço sob o efeito de EAI.

Nos restantes sujeitos da amostra, 2 (p-valor $=0,03), 4(p$-valor $=0,04), 5(p$-valor $=0,01), 7$ $(\mathrm{p}$-valor $=0,00), 9(\mathrm{p}$-valor $=0,00)$ e $11(\mathrm{p}$-valor $=0,02$ ), não se verificou uma homogeneidade das amostras entre os vários estudos realizados, o que significa que nestes casos, houve alteraçôes significativas na distribuição da velocidade do serviço quando constrangidos com o EAI.
A fim de determinar o sentido da relação entre o EAI e a velocidade de saída bola, recorreu-se ao coeficiente de correlação $\rho$ de Spearman, tendo-se verificado uma medida negativa nas correlaçōes em oito participantes $(1,2,4,7,8,9,11$ e 12), i.e., com o aumento do EAI (variável ordinal de sem AEI a EAI aleatório) notou-se um decréscimo da velocidade do serviço. Contudo, apenas nos sujeitos $2(\rho=-0,336, P<0,05), 4(\rho=$ $-0,197, \mathrm{P}<0,05), 7(\rho=-0,206, \mathrm{P}<0,05)$ e $11(\rho=$ $-0,231, \mathrm{P}<0,05)$, os valores de $\rho$ foram considerados significativos da existência de correlação entre variáveis.

\section{Análise inter-individual}

Ao analisar-se como amostras independentes os 240 serviços, relativos aos 12 participantes, por condição de prática, provou-se a normalidade do RE a partir do teste de Kolmogorov-Smirnov. O fato de tratar-se de uma distribuição Gaussiana permitiu o recurso da Análise de Variância univariada (ANOVA) e verificou-se não existirem diferenças no RE entre as 
cinco condições de prática, ou seja, o EAI igualmente não constrangeu o RE quando analisado intercondições de prática $\left(\mathrm{F}_{4,1195}=1,116\right.$, $\mathrm{p}$-valor $\left.=0,347\right)$.

Relativamente à variável dependente, velocidade de saída da bola, não se verificou uma distribuição Gaussiana no estudo sem EAI e EAI 2, o que conduziu à utilização do teste não paramétrico, de Kruskal-Wallis. Os resultados desta análise inter-individual, igualmente não evidenciaram a existência de diferenças na distribuição de probabilidade entre si ( $p$-valor $=0,125)$.
No que concerne à relação entre a velocidade e o RE (exatidão) constata-se a existência de correlações negativas e estatisticamente significativas, entre estas duas variáveis nas condições com EAI1, EAI3 e EAI aleatório (TABELA 3), ou seja, quando aumenta a velocidade do serviço decresce o RE e vice-versa. Nos estudos EAI 0 e EAI 2, utilizou-se o coeficiente de correlação de Spearman pelas razões anteriormente invocadas e para os restantes estudos aplicou-se o coeficiente de correlação de Pearson.

TABELA 3 - A relação entre as variáveis de velocidade da bola e RE nos cinco estudos.

\begin{tabular}{lccccc}
\hline & $\begin{array}{c}\text { Velocidade } \\
\text { EAI 0 }\end{array}$ & $\begin{array}{c}\text { Velocidade } \\
\text { EAI 1 }\end{array}$ & $\begin{array}{c}\text { Velocidade } \\
\text { EAI 2 }\end{array}$ & $\begin{array}{c}\text { Velocidade } \\
\text { EAI 3 }\end{array}$ & $\begin{array}{c}\text { Velocidade } \\
\text { EAI a }\end{array}$ \\
\hline RE - EAI 0 & $-0,105$ & & & & \\
RE - EAI 1 & & $-0,132^{*}$ & & & \\
RE - EAI 2 & & & $-0,109$ & & $-0,164^{*}$ \\
RE - EAI 3 & & & & $-0,202^{*}$ \\
RE - EAI al & & & & & \\
\hline
\end{tabular}

* Correlação significativa para $a=0,05$.
Na FIGURA 5 apresenta-se o referencial associado às condições de prática realizadas e representa a elipse melhor ajustada, no sentido dos mínimos quadrados, ao conjunto das coordenadas das posições do primeiro quique no serviço dos 12 jogadores para as cinco condições de EAI. Em primeiro lugar, verifica-se que a orientação dos eixos das elipses obtidas é, de grosso modo, semelhante em todos os casos, o que indicia que o constrangimento não altera, de forma significativa, a direção de serviço. Nota-se, também, que da situação sem vento para a situação de EAI 1 dáse um acréscimo nas dimensões da elipse de erro o que leva a uma maior dispersão de valores. No entanto, observa-se que para as situações seguintes (intensidade crescente e aleatória do escoamento) se dá uma ligeira diminuição dos comprimentos dos eixos das elipses.

O erro é maior na profundidade do serviço do que propriamente na sua direção, o que corrobora o que foi já descrito anteriormente para o AR, RE, VE e E. De outro modo, constata-se que a precisão dos jogadores quando servem do lado direito e para o " $\mathrm{T}$ ” apresenta graficamente uma tendência para o estreitamento das elipses de mínimos quadrados em todas as condições de prática realizadas.

Por fim, observa-se também que todas as elipses de erro não estão centradas na origem do referencial (alvo) mas sim desenvolvem-se prioritariamente no primeiro quadrante do referencial, i.e., os jogadores privilegiam a eficácia em relação ao menor erro radial. 


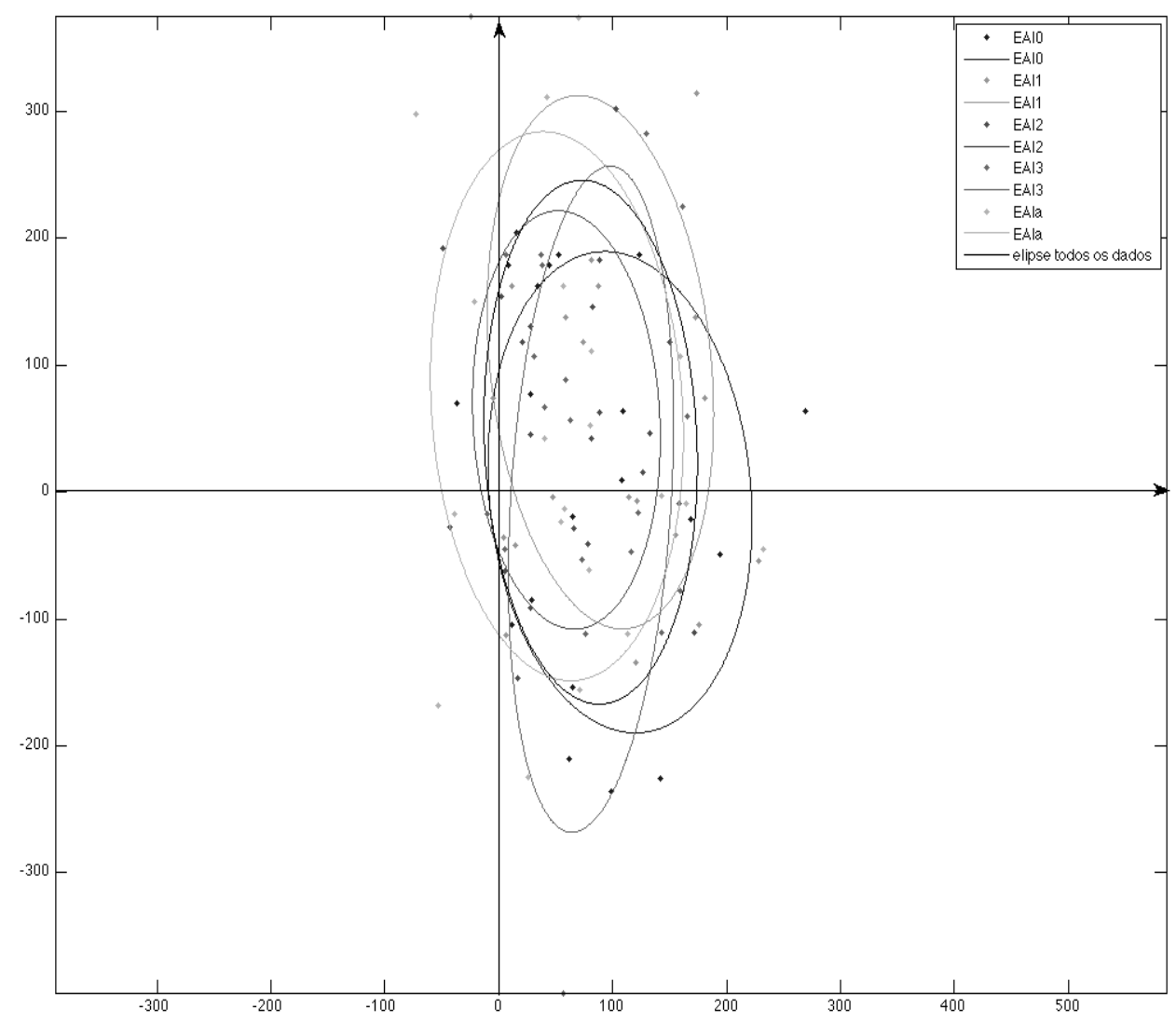

FIGURA 5 - As elipses de mínimos quadrados para as posições relativas ao alvo nas diversas condições de escoamento aerodinâmico (240 serviços analisados por estudo). Cada elipse corresponde a uma condição de prática.

\section{Discussão}

O pressuposto de que o vento é um fator ambiental importante no rendimento do primeiro serviço (Mendes et al., 2011) e o fato de diversos autores reforçarem a importância desta variável em contexto de treino e de competição (ELLIOTT, REID \& CRESPO, 2009; FAULKNER, 1997; FlANAGAN, 1983; Hoskins, 2003; Loehr, 1996; Scott \& Randy, 2000) foi, em termos teóricos, a base desta pesquisa.

O presente estudo pretendia analisar as variáveis de produto no serviço de tênis através de jogadores experientes, quando constrangidos com um escoamento aerodinâmico induzido. Esperava-se encontrar diferenças estatisticamente significativas na exatidão e precisão ao longo das diferentes velocidades de EAI, verificando igualmente se os aspectos da variabilidade intra e inter-individual emergiam das variáveis de produto, designadamente através do estudo da exatidão e da velocidade de saída da bola no primeiro serviço.

Os resultados obtidos sugerem que a aplicação de diferentes velocidades "de vento lateral artificial" impostas pelo escoamento aerodinâmico induzido, não se traduziram em diferenças estatisticamente significativas nas variáveis exatidão e precisão. Ou seja, o pressuposto inicial de que podia existir uma relação direta entre a variabilidade das condições de prática (i.e., intra e inter-individual) e o envolvimento onde esta se desenvolve não foi confirmado neste estudo para as referidas variáveis. Contudo, foi perceptível em todos os jogadores durante as cinco condições de prática realizadas, uma maior exatidão e precisão na direção do serviço (eixo dos $x$ ) e menor na profundidade, independentemente da presença ou não de "vento lateral". O estudo realizado por CARLTON, CHOw e SHIM (2006), que compara o primeiro e segundo serviço de jogadores de elite mundial em situação competitiva, confirma os resultados encontrados. O jogador perito quando pretende servir para a zona central, procura variar o menos possível na direção de serviço, defendendo-se de eventuais oscilações 
neste eixo e que condicionariam a eficácia do seu serviço, em contexto competitivo. Relativamente à profundidade do serviço, como a margem de erro é maior (6,4 m de distância entre a linha central e a rede), o jogador apresenta uma maior variabilidade. Neste seguimento, o treinamento da direção do serviço deve ser privilegiado no processo de formação esportiva dos tenistas.

O sistema de medida alternativo ao discreto (Cauraugh, Gabert \& White, 1990; Johnson, 1957; Menayo et al., 2008; Signorile et al., 2005) foi capaz de determinar quer as coordenadas reais do primeiro quique na quadra de tênis (CARLTON, Chow \& Shim, 2006; Menayo, 2010; Menayo, Moreno, Fuentes \& Damas, 2006; Mendes et al., 2010b), quer a penalização a atribuir às tentativas que intersetassem a rede e a consequente atualização das coordenadas relativas (por penalização) aos primeiros quiques na quadra de tênis dessas tentativas. Este último procedimento permitiu a não repetição de 264 serviços que tocaram na rede num total de 1200 realizados nas cinco condições, o que evitou eventuais estados de fadiga e de desmotivação dos participantes.

Os dados mostram que relativamente à velocidade de saída da bola, seis participantes apresentaram uma tendência com o incremento de EAI ("vento lateral artificial”) em servir com menos potência, mantendo estável a exatidão e precisão. Tal fato poder-se-á explicar no contexto competitivo, onde a exatidão e a precisão do serviço são fatores determinantes para o rendimento esportivo (Bollettieri, 2001; Fuentes; Menayo, 2009; United States Tennis Association, 2004).

De acordo com os resultados obtidos, a velocidade e a exatidão relacionam-se de uma forma inversa na presença de EAI, excepto na condição EAI2 (4,3 m/s). Contrariamente, JoHNSON (1957) não confirmou a existência de relaçôes entre a exatidão e a velocidade de serviço em jogadoras de elite, o mesmo sucedendo com KNUDSON et al. (2004) no estudo realizado com jogadores principiantes e experientes, onde concluíram que o treinamento da força não afeta a velocidade e a exatidão. Mais recentemente CARLTON, CHOW e SHIM (2006) também não encontraram qualquer relação com jogadores profissionais em situação de jogo tanto no primeiro como no segundo serviço.

Por outro lado, Cauraugh, Gabert e White (1990), na investigação levada a cabo com tenistas experientes de ambos os sexos e onde variaram diretamente a velocidade de serviço, verificaram melhorias na exatidão quando serviam a partir de $70 \%$ a $90 \%$.

No entanto, verificou-se na pesquisa desenvolvida neste artigo, uma correlação negativa entre a velocidade e a exatidão no primeiro serviço, confirmando as conclusōes do estudo de ATKINSON e SPEIRS (1998) sobre o efeito da variação diurna na velocidade e exatidão do primeiro e segundo serviço. Também MenaYo et al. (2008) encontraram diferenças estatisticamente significativas em tenistas de aperfeiçoamento quando serviram à mínima e máxima potência e uma correlação negativa e significativa entre os serviços realizados à mínima potência e a exatidão obtida.

Atendendo à importância que as variáveis de produto aqui analisadas têm nos métodos de treinamento de potência, de exatidão e de precisão no serviço (MENDEs et al., 2011), os resultados apresentados podem ser úteis para o delineamento das tarefas de treinamento em tenistas de competição.

O delineamento experimental utilizado neste estudo, embora aproxime o serviço da situação real da sua execução num jogo de tênis, necessita de ser aprimorado de forma a obter resultados mais robustos e consistentes. Assim, diversos fatores podem justificar os resultados obtidos, designadamente: as caraterísticas da amostra, a organização e quantidade de prática, a especificidade e o grau de complexidade da tarefa e a estrutura e organização das sessōes. Saliente-se que estes aspectos já tinham sido evidenciados no estudo de outras habilidades motoras, nomeadamente no golfe, através do movimento "putting" (ver, como exemplo, os trabalhos de Mendes, Martins \& Dias, 2008; Dias \& Mendes, 2010).

A razão para a não verificação de diferenças estatisticamente significativas entre executantes para a exatidão e precisão, poder-se-á explicar pela importância que a estabilização destas variáveis têm no treino dos jogadores peritos na colocação da bola no serviço (ForTi, 1995; Fuentes, 2001; United States Tennis Association, 2004). Uma outra justificação para os resultados encontrados pode estar no fato dos sujeitos terem sido "constrangidos" face aos vários instrumentos utilizados no contexto do desempenho motor. Por outras palavras, os diversos instrumentos usados nesta pesquisa podem ter inibido ou condicionado os jogadores no decorrer $\mathrm{da}$ tarefa. Todavia, o fato desta amostra ser constituída por sujeitos experientes, podia, neste entendimento, ter sido suficiente para contornar este fenômeno.

A quantidade de prática é outra variável que pode ter influenciado os resultados obtidos. De acordo com TANI (2005) tarefas desta natureza parecem necessitar de uma quantidade de prática assinalável, principalmente quando se pretendem aferir aspectos relacionados com variabilidade intra e interindividual. Acrescente-se, segundo a perspectiva 
do mesmo autor, que um volume de prática mais elevado podia ter permitido aos executantes atingir elevados graus de proficiência e, presumivelmente, confirmar os pressupostos em análise.

Apesar da tarefa estudada ter respeitado o quadro regulamentar da modalidade, não é totalmente representativa, pois realizou-se num contexto experimental. Com efeito, os constrangimentos resultantes dos próprios dispositivos instrumentais podem de alguma maneira anular a "vantagem" dos peritos, seja porque lhes retira informação que normalmente utilizam, ou porque os expõe a um tipo de informação diferente (ABERneTHY, THOMAS \& THOMAS, 1993; Singer, Williams, Frehlich, Janelle, Radlo, BARBa \& BOUCHARD, 1998). Como exemplo do exposto, o estudo realizado por IDA, KUSUBORI e ISHII (2005) encontrou diferenças na performance do "soft smash" no tênis entre as condiçôes de prática laboratorial e da prática competitiva.

Também a complexidade da tarefa pode ter influenciado os resultados obtidos, uma vez que esta, ao ser balística, é de difícil execução. Importa assim investigar de que forma os constrangimentos da tarefa, do envolvimento e do praticante podem ser estudados à luz dos pressupostos teóricos enaltecidos por NeWell (1986), referenciando as implicações práticas que os mesmos apresentam em futuros trabalhos desta natureza. Este tipo de abordagem será passível de certificar como é que os executantes auto-organizam o sistema motor face a diversos constrangimentos (e.g., vento, entre outros impostos pelo experimentador) (cf. AraúJo, 2006). Dito de outro modo, urge analisar as medidas de processo no estudo de movimentos balísticos, onde, em traços gerais, a maioria dos trabalhos conhecidos abordam a medida estrita da performance e produto, tendo como referencial teórico fundamental as teorias cognitivas clássicas (e.g., ADAMS, 1971; SCHMIDT, 1975).

Face aos resultados obtidos neste estudo, é relevante investigar o serviço de tênis com sujeitos

\section{Conclusão}

Os resultados obtidos permitem concluir que embora a exatidão e a precisão do serviço de tênis executado por peritos apresentem um padrão de variabilidade estável mesmo sob o efeito de "vento lateral", não existe uma relação direta entre a variabilidade das condiçôes de prática (i.e., intra e interindividual) e o envolvimento onde esta se desenvolve. inexperientes e compará-los com indivíduos que apresentem níveis de experiência mais elevados (e.g., "novices" versus "experts"). Tendo em conta o número limitado de estudos sobre a análise das variáveis deste trabalho, importa aferir se o "controle" ou "manipulação artificial" do vento através dos dispositivos experimentais anteriormente apresentados são passíveis de ser aplicados em outras habilidades motoras, designadamente aquelas que apresentem caraterísticas balísticas (e.g., drive do Golfe ou o batimento de Basebol).

A ampliação do estudo a outras direções de vento em futuras investigações, teria uma grande utilidade para os treinadores. Contudo, o dispositivo experimental aqui desenvolvido não permite recriar o vento contra, atendendo ao impacto visual do ventilador no excutante (variável contaminante). Por outro lado, o vento a favor, igualmente não seria possível "produzi-lo" por limitaçôes do espaço coberto. Seria necessário posicionar o dispositivo a $4 \mathrm{~m}$ de distância atrás do jogador, distância essa inexistente na quadra coberta. Atendendo às caraterísticas do ventilador industrial utilizado que pressupóe uma ligação trifásica, apenas se dispunha de um espaço coberto na região de Coimbra capaz de responder as estas exigências técnicas.

Por outro lado, mesmo que o dispositivo utilizado recriasse as referidas condições de prática (vento contra e a favor), a análise da variável de produto, velocidade máxima, ficaria comprometida, ao comparar-se a condição sem vento com as restantes condiçōes com vento. Os dados seriam "contaminados" pelo fato do vento a favor beneficiar o servidor e o vento contra ter um efeito inverso.

Relativamente à relevância do constrangimento do vento lateral no desempenho do serviço, BRODY (1987), American Sport Education Program (2009), Hoskins (2003) e Scott e Randy (2000) analisam com o mesmo grau de importância as três direções de vento: a favor, contra e lateral.

A aplicação de diferentes velocidades vento impostas pelo escoamento aerodinâmico induzido não se traduziu em diferenças estatisticamente significativas, apesar das alterações que produzem no comportamento da bola durante o lançamento no serviço, confirmadas por MENDES, LuZ, CouCEIRO, IGLÉSIAS, Ferreira, Sismeiro, Mendes e Fuentes (2010c). 
Relativamente à velocidade da bola no serviço, alguns jogadores experientes da amostra quando constrangidos pelo "vento lateral artificial", diminuíram a potência do serviço, o que em parte, confirma a relevância da colocação da bola no processo de treino, como um fator determinante para dificultar a resposta ao serviço pelo opositor (FORTI, 1995; FUENTES, 2001; United States Tennis Asociation, 2004).

No âmbito do controle motor, o princípio da lei de FiTTs (1954) constitui uma referência incontornável na abordagem às duas variáveis aqui investigadas. No caso concreto do serviço, a relação inversa entre a velocidade e a exatidão foi verificada na presença de "vento lateral", confirmando os resultados encontrados por ATKINSON e SPEIRS (1998) que igualmente estudaram um constrangimento de envolvimento, jogadores a servirem em diferentes momentos do dia (variação diurna). Neste seguimento, MEnAYO et al. (2008) também encontraram uma correlação negativa em tenistas de aperfeiçoamento quando serviram à mínima potência, entre a velocidade e a exatidão.

Os dispositivos experimentais utilizados aproximam o serviço da situação real da sua execução num jogo de tênis. Contudo, estes necessitam de ser melhorados de forma a obter resultados mais robustos e consistentes. Importa ainda verificar neste contexto de que forma os constrangimentos $\mathrm{da}$ tarefa, do envolvimento e do praticante podem ser estudados com base no modelo de constrangimentos de Newell (1986).

Por último, a aplicabilidade deste protocolo não se esgota no delineamento experimental deste estudo, podendo ser utilizado em outras situações de prática motora e com diferentes gestos técnicos do tênis.

\begin{abstract}
Analysis of the performance in the first serve in competitive tennis players under the effect of the induced aerodynamic flow

This study analysed the product variables on the tennis serve of 12 experienced players, when constrained by an induced streamlined flow (EAI), delivered by an industrial ventilator. In order to obtain the serve accuracy, we use 2D analysis. Moreover, the ball's speed was measured by radar. The players performed 100 services at maximum speed and to the intersection point between the central and the service lines. The results showed no statistically significant changes in accuracy and precision between the control condition and the four EAl conditions. The results also showed prominent statistical changes in the serve speed for 6 among the 12 players. Concerning to the relation between the serve's speed and the accuracy, the results showed the existence of negative significant correlations for the speeds EA1, EAI3 and for random EAI. Lastly, the players' attempts had narrower accuracy and precision in the depth than in the serve direction.
\end{abstract}

UnItERMs: Variability; Accuracy; Precision; Motor control; Tennis.

\title{
Resumen
}

Análisis del rendimiento del primer servicio en tenistas de competición bajo la influencia de flujo aerodinámico inducido

Este estudio analizó las variables del producto en el servicio de tenis en 12 jugadores expertos, cuando se les aplica un flujo aerodinámico inducido (EAl) mediante un ventilador industrial. Se calculó la precisión del servicio aplicando un análisis 2D. La velocidad de salida de la bola fue medida con un radar. Los sujetos realizaron 100 servicios a máxima velocidad hacia la línea de intersección entre la línea central y de servicio. Los resultados no muestran diferencias significativas en la exactitud y precisión entre la condición de control y las cuatro condiciones con EAl. En la variable de velocidad del servicio se encontraron diferencias significativas en 6 participantes. Se hallaron correlaciones negativas y significativas entre la velocidad y la 
precisión entre las condiciones EAl1; EAl3 y EAl aleatorio. Los jugadores presentaron una menor exactitud y precisión en profundidad y mayor en la dirección del servicio.

Palabras clave: Variabilidad; Precisión; Exactitud; Control motor; Tenis.

\section{Referências}

ABERNETHY, B.; THOMAS, K.T.; THOMAS, J.T. Strategies for improving understanding of motor expertise (or mistakes we have made and things we have learned!!). In: STARKES, J.L.; ALLARD, F. (Eds.). Handbook of research on sport psychology. New York: MacMillan, 1993. p.129-70.

ADAMS, J.A. A closed-loop theory of motor learning. Journal of Motor Behavior, Washington, v.3, n.2, p.111-50, 1971. ALVES, A.S. Metrologia geométrica. Lisboa: Fundação Calouste Gulbenkian, 1996.

AMERICAN SPORT EDUCATION PROGRAM. Coaching tennis technical and tactical skills. Champaign: Human Kinetics, 2009.

ARAÚJO, D. Tomada de decisão no desporto. Lisboa: Edições FMH, 2006

ARAÚJO, D.; CARVALHO, J. A tomada de decisão no ténis. In: PEZARAT CORREIA, P.; COUTINHO, C. (Eds.). Investigação e ténis. Lisboa: Edições FMH, 2007. p.85-102.

ATKINSON, G.; SPEIRS, L. Diurnal variation in tennis service. Perceptual and Motors Skills, Missoula, v.86, p.1335-8, 1998. BOLLETTIERI, N. Bollettieri's tennis handbook. Champaign: Human Kinetics, 2001.

BONNEFOY, A.; SLAWINSKI, J.; LEVEQUE, J.M.; RIQUET, A.; MILLER, C. Relationship between the vertical racquet head height and the lower limb motions of elite players' flat serve. Computer Methods in Biomechanics and Biomedical Engineering, v.12, n.1, p.55-7, 2009.

BRASIL. Ministério da Indústria, do Comércio e do Turismo. Instituto Nacional de Metrologia, Normalização e Qualidade Industrial. INMETRO, Vocabulário de Termos Fundamentais e Gerais de Metrologia, Portaria INMETRO n. 029, de 10 de Março de 1995. Brasília: INMETRO, 1995.

BRODY, H. Tennis science for tennis players. Philadelphia: University of Pennsylvania Press, 1987. . Serving strategy. ITF Coaching and Sport Science Review, London, v. 31, p. 2-3, 2003.

CARLTON, L.G.; CHOW, J.W.; SHIM, J. Variability in motor output and Olympic performancers. In: DAVIDS, K.; BENNETT, S.; NEWELL, K. (Eds.). Movement system variability. Champaign: Human Kinetics, 2006. p.85-108.

CAURAUGH, J.H.; GABERT, T.E.; WHITE, J.J. Tennis serving velocity and accuracy. Perceptual and Motor Skills, Missoula, v.70, p.719-22, 1990.

DIAS, G.; MENDES, R. Efeitos do contínuo de níveis de interferência contextual na aprendizagem do "putt" do golfe. Revista Brasileira de Educação Física e Esporte, São Paulo, v.24, n.4, p.545-53, 2010.

ELLIOTT, B.; REID, M.; CRESPO, M. Technique development in tennis stroke production. London: International Tennis Federation, 2009.

FAULKNER, T. Read the 'breaks' on a windy day. Tennis, London, v.33, n.1, p.42, 1997.

FITTS, P. M. The information capacity of the human motor system in controlling the amplitude of movement. Journal of Experimental Psychology, Washington, v.47, p.381-91, 1954.

FLANAGAN, P. Playing in windy conditions: it is essential to alter your style to fit the conditions. Athletics Coach, [S.l.], v.63, n.9, p.12-3, 1983.

FORTI, U. Curso de tennis. Barcelona: Editorial De Vecchi, 1995.

FUENTES, J.P. Análisis de la formación y de los planteamientos didácticos del entrenador de ténis de alta competicion en Espana. 2001. 820f. Dissertação (Doutoramento em Ciencias del Deporte) - Facultad de Ciencias del Desporte, Universidad de Extremadura, Cáceres, 2001.

FUENTES, J.P; MENAYO, R. Los golpes del tenis: de la iniciación al alto rendimento. Sevilha: Wanceulen Editorial Deportiva, 2009.

GIRARD, O.; MICALLEF, J.; MILLET, G.P. Influence of restricted knee motion during the flat first serve in tennis. Journal of Strength and Conditioning Research, Champaign, v.21, n.3, p.950-7, 2007.

. Lower-limb activity during the power serve in tennis: effects of performance level. Medicine and Science in Sports and Exercise, Madison, v.37, n.36, p.1021-9, 2005. 
GODINHO, M.; MENDES, R.; MELO, F.; BARREIROS, J. Controlo motor e aprendizagem: trabalhos práticos. Cruz Quebrada: Faculdade de Motricidade Humana Serviço de Ediçōes, 2000.

HAAKE, S.J.; CHADWICK, S.G.; DIGNALL, R.J.; GOODWILL, S.; ROSE, P. Engineering tennis: slowing the game down. Sports Engineering, London, v.3, n.2, p.131-43, 2000.

HOSKINS, T. The tennis drill book. Champaign: Human Kinetics, 2003.

IDA, H.; KUSUBORI S.; ISHII, M. Kinematics and kinetics of the racket-arm during soft-tennis smash under match conditions. Journal of Applied Biomechanics, Champaign: v.21, p.334-47, 2005.

INSTITUTO PORTUGUÊS DA QUALIDADE. Vocabulário internacional de metrologia, VIM: guia ISO/IEC 99:2007 - versão portuguesa. Caparica: IPQ, 2007.

INTERNATIONAL ORGANIZATION FOR STANDARDIZATION. ISO/ IEC Guide 99-12:2007 International vocabulary of metrology: basic and general concepts and associated terms VIM, BIPM e ISO. Geneva: ISO/IEC, 2007. JOHNSON, J. Tennis serve of advanced woman players. Research Quarterly, Washington, v.28, p.123-31, 1957.

KNUDSON, D.; NOFFAL, G.; BAHAMONDE, R.; BAUER, J.; BLACKWELL, J. Stretching has no effect on tennis serve performance. Journal of Strength and Conditioning Research, Champaign, v.3, n.18, p.654-6, 2004.

LEES, A. Science and the major racket sports: a review. Journal of Sports Sciences, London, v.21, n.9, p.707-32, 2007.

LOEHR, J. How to battle the elements. Tennis, London, v.32, n.7, p.40, 1996.

MENAYO, R. Análisis de la relación entre la consistencia en la ejecución del patrón motor del servicio en tenis, la precisión y su aprendizage en condiciones de variabilidad. 2010. 313f. Dissertação (Doutoramento em Ciencias del Deporte) - Facutad de Ciencias del Desporte, Universidad de Extremadura, Cáceres, 2010.

MENAYO, R.; FUENTES, J.P.; MORENO, F.J.; CLEMENTE, R.; GARCÍA CALVO, T. Relación entre la velocidad de la pelota y la precisión en el servicio plano en tenis en jugadores de perfeccionamento. Motricidad European Journal of Human Movement, Granada, v.21, p.17-30, 2008.

MENAYO, R.; MORENO, F.J.; FUENTES, J.P.; DAMAS, J.S. Propuesta de un protocolo de medida para a valoración del rendimiento y la consistencia en la ejecución del servicio en tenis. In: CONGRESO NACIONAL DE CONTROL MOTOR, 1., 2006, Melilla. Livro de Actas... Melilla: [s.ed.], 2006.

MENDES, P.C.; LUZ, M.; COUCEIRO, M.; IGLÉSIAS, P.; FERREIRA, A.; SISMEIRO, J.; MENDES, R.; FUENTES, J.P. Analysis of the wind influence in tennis serve. In: MATHEMATICAL METHODS IN ENGINEERING 2010 INTERNATIONAL SYMPOSIUM, Coimbra, 2010. Atas..... Coimbra: [s.ed.], 2010c.

MENDES, P.C.; MENDES, R.; FUENTES, J.P.; CAMPOS F.; ARAÚJO, D. Fatores de rendimento no primeiro serviço em tenistas de competição. Revista da Educação Física, Maringá, v.22, n.3, p.315-26, 2011.

MENDES, P.C.; MENDES, R.; MARTINS, F.; FACAS VICENTE, A.; FUENTES, J.P. Aprendizagem motora e ténis: medida de precisão no serviço de ténis. Brazilian Journal of Motor Behavior, Porto Alegre, v.5, p.17, $2010 \mathrm{~b}$.

MENDES, P.C.; SIMŌES, H.; MENDES, R.; TROVÃO, J.; LUZ, M.; COUCEIRO, M.S.; FERREIRA, N.; DIAS, G.; FUENTES, J.P. Influência do ambiente acústico no desempenho do tenista sob o efeito de um escoamento aerodinâmico induzido. In: CONGRESSO INTERNACIONAL DE SAÚDE AMBIENTAL, Coimbra, 2010. Atas... Coimbra: [s.ed.], 2010a. p.74. MENDES, R.; MARTINS, R.; DIAS, G. Effects of a contextual interference continuum on golf putting task. In: ANNUAL CONGRESS OF THE EUROPEAN COLLEGE OF SPORT SCIENCE, 13., 2008, Estoril. Book of abstracts... Estoril: ECSS, 2008. A-490.

NEWELL, K.M. Constraints on the development of coordination. In: WADE, M.G.; WHITING, H.T.A. (Eds.). Motor skill acquisition in children: aspects of coordination and control. Amsterdam: Martinies NIJHOS, 1986. p.341-60.

ORGANISATION MONDIALE DE LA SANTÉ. Le bruit au travaile et le brui ambient: aidé-mémoire. Genéve: OMS, 2002. PUGH, S.F.; KOVALESKI, J.E.; HEITMAN, R.J.; GILLEY, W.F. Upper and lower body strength in relation to ball speed during a serve by male collegiate tennis players. Perceptual and Motor Skills, Missoula, v.97, p.867-72, 2003.

SCHMIDT, R.A. A schema theory of discrete motor skill learning. Psychological Review, Washington, v.82, n.4, p.225-60, 1975.

Motor control and learning. Champaign: Human Kinetics, 1988.

SCOTT, W.; RANDY, P. Serious tennis. Champaign: Human Kinetics, 2000.

SIGNORILE, J.F.; SANDLER, D.J.; SMITH, W.N.; STOUTENBERG, M.; PERRY, A.C. Correlation analyses and regression modelling between isokinetic testing and on-court performance in competitive adolescent tennis players. Journal of Strength and Conditioning Research, Champaign, v.19, p.519-26, 2005.

SINGER, R.N.; WILLIAMS, A.M.; FREHLICH, S.G.; JANELLE, C.M.; RADLO, S.J.; BARBA, D.A.; BOUCHARD, L.J. New frontiers in visual search: an exploratory study in live tennis situations. Research Quarterly for Exercise and Sport, Washington, v.69, n.3, p.290-6, 1998. 
TANABE, S.; ITO, A. A three-dimensional analysis of the contributions of upper limb joint movements to horizontal racket head velocity at ball impact during tennis serving. Sports Biomechanics, London, v.6, n.3, p.418-33, 2007.

TANI, G. Comportamento motor: aprendizagem e desenvolvimento. Rio de Janeiro: Guanabara Koogan, 2005.

UNITED STATES TENNIS ASSOCIATION. Coaching tennis successfully. 2a ed. Champaign: Human Kinetics, 2004. VAN DEN TILLAR, R.; ETTEMA, G. Instructions emphasizing, velocity, accuracy, or both in performance and kinematics of overarm throwing by experienced team handball players. Perceptual and Motor Skills, Missoula, v.97, p.731-42, 2003.

\begin{tabular}{r|l} 
ENDEREÇO & \\
Pedro Cabral Mendes & Recebido para publicação: 03/01/2011 \\
Instituto Politécnico de Coimbra & 1a. Revisão: 24/ 10/2011 \\
Escola Superior de Educação de Coimbra & 2a. Revisão: 12/01/2012 \\
Praça Heróis de Ultramar & 3a. Revisão: 23/02/2012 \\
3030-329 - Coimbra - PORTUGAL & 4a. Revisão: 27/02/2012 \\
e-mail: pmendes@esec.pt & Aceito: 05/03/2012 \\
& \\
\hline
\end{tabular}

